\title{
Nigella Sativa Prevented Parkinson's-Like Motor Functions Impairment, Dopamine Depletion and Neuronal Degeneration in the Striatum of Mptp- Induced Balb/C Mice
}

Royhaan Folarin ( $\nabla$ royhaan.folarin@oouagoiwoye.edu.ng )

Olabisi Onabanjo University https://orcid.org/0000-0003-1558-6158

Akinola Olonade

Near East University: Yakin Dogu Universitesi

Imam Aminu

University of llorin

Praise Ogunkunle

Olabisi Onabanjo University

Paul Folarin

Olabisi Onabanjo University

\section{Research Article}

Keywords: Nigella sativa, MPTP, BALB/c, Parkinsonism, Selectivity, Striatum, Frontal cortex

Posted Date: June 17th, 2021

DOI: https://doi.org/10.21203/rs.3.rs-522823/v1

License: (c) (1) This work is licensed under a Creative Commons Attribution 4.0 International License.

Read Full License 


\section{Abstract \\ Background}

Parkinsonism is a neurological disease characterised by dopaminergic neuron degeneration in the substantial nigra and dopamine deficiency in the brain, with motor and psycho-cognitive implications, while limitations masked the efficacy of the available drugs, thus the need to find alternatives with less side effects are essential. Nigella sativa is a multi-potent plant with therapeutic potentials in the brain and other body organs. This study investigated the effects of Nigella sativa oil (NSO) on the cognitive and other Parkinsonism endophenotypes elicited by MPTP in the BALB/c strain mice.

\section{Materials and Methods}

Body weights, brain-body ratios, recognition memory (through novel object recognition test), as well as fronto-cortical, striatal and cerebellar dopamine and neuronal density were assayed in thirty-two (32) male BALB/c mice $(18 \mathrm{~g}-25 \mathrm{~g})$. They were randomized into four groups exposed to; normal feed, 18 $\mathrm{mg} / \mathrm{kg}$ MPTP i.p, $1 \mathrm{ml} / \mathrm{kgbw}$ NSO p.o., and NSO + MPTP respectively, for 5 consecutive days. Behaviours were analysed 24 hours after the last exposure, subsequently euthanized, the brains removed and processed for biomarkers analysis and histochemistry.

\section{Results}

Parkinsonism-like traits such as mild tremor, down-regulation of striatal and fronto-cortical dopamine and neurons were recorded in the BALB/c mice administered with MPTP only. However, significant increase ( $p$ $<0.05$ ) in appetite, body weight, brain-body weight ratio, and recognition memory was also recorded in the MPTP-administered mice, though Nigella sativa was significantly prophylactic against the negative Parkinsonic features, and 'moderative' of the up-regulations induced by MPTP.

\section{Conclusion}

While this suggests selective MPTP sensitivity and resistance in BALB/c strains, this study recommends the investigation of possible (though ironic) beneficial potentials of MPTP.

\section{Introduction}

Parkinson's disease (PD) is a degenerative disorder of the central nervous system that mainly affects the motor system (NINDS, 2019). It is characterised by progressive neuronal degeneration which predominantly affects the dopaminergic neurons in the nigrostriatal system and several other regions of the brain (Roberts et al., 1994). The exact cause of Parkinson's disease (PD) is unknown, but epidemiological studies suggest an association with environmental toxins. Early in the disease, the most 
obvious symptoms are rigidity, difficulty with walking, affected thinking and other behavioural problems (NINDS, 2019). Other symptoms include sensory, sleep, and emotional problems. The main motor symptoms are collectively called "Parkinsonism", or a "Parkinsonian syndrome" (Williams \& Litvan, 2013).

The striatum is a principal component of the basal ganglia, mostly studied for its roles in facilitating voluntary movement, rewards and motivations, but with now recognised influences in cognition and other behaviours (Dingman, 2015). Furthermore, the neuronal degeneration and behavioural deteriorations in Parkinson's disease is evidently shown to be unlimited to the basal ganglia due to the observed nonmotor symptoms, but to other high function areas of the brains, like the frontal cortices and cerebellum with established structural and functional communications with the basal ganglia (Drag et al., 2009) (Ichinohe et al., 2000).

The cerebellum has also been reported with pathological changes in Parkinson's disease, even though its major roles are thought to include pathological and compensatory effects. This is as morphological and functional or modulations were detected in the cerebellum in relation to tremor, akinesia/rigidity, gait disturbance, dyskinesia and some non-motor symptoms(Wu \& Hallett, 2013).

Dopamine supplementation remain the most efficient therapy in management of, and/or slowing the progressions of Parkinson's diseases, with extensive undesired outcomes. Thus, the search for alternative or supplementary regimen, to further slow the disease progression, prevent, rescue or salvage the degenerating dopaminergic systems. Nigella sativa is one of the most widely used medicinal plants across the world (Ahmad et al., 2013), with a long history of use across ancient Egyptian, Indian (Unani), Greek (Ayurvedic), Roman and Islamic cultures (Al-Naqeep et al., 2011). With therapeutic effects on several body systems in humans and animals (Assi et al., 2016), Nigella sativa has also proven useful in the treatment of psychiatric disorders (Randhawa \& Alenazi, 2016). However, due to the paucity of information on its impacts on MPTP-induced Parkinson-like symptoms, particularly on striatal, frontocortical and cerebellar parameters, this research aimed at filling this knowledge gap.

This study thus investigates the possible neuro-therapeutic roles of Nigella sativa oil in Parkinson's-like endophenotypes, through the analyses of dopamine levels, neuronal density and histopathology of the striatum, frontal cortex and cerebellum and associated functions in MPTP exposed BALB/c mice.

\section{Materials And Methods}

\subsection{Acquisition of research materials}

Sixty (60) mls of purified Nigella sativa oil was procured from Hemani® International, Pakistan. Similarly, 1-methyl-4-phenyl-1-2-3-6-tetrahydropyridine (MPTP) was procured from Medchem Express, New Jersey, USA.

The forty-eight (48) adult male BALB/c mice used for the study (with weight ranging from $18 \mathrm{~g}$ to $25 \mathrm{~g}$ ) were in-bred at the Neurophytotherapy research lab (NPTRL) in the faculty of Basic Medical Sciences, 
where they were housed in well ventilated cages improvised at the lab and under controlled temperature and humidity.

\subsection{Experimental Design and Dosing}

The mice were allowed to acclimatise for one week, randomly divided into four (4) groups, containing twelve mice each, and exposed to; normal feed (Control group), $18 \mathrm{mg} / \mathrm{kg}$ MPTP intraperitoneal (MPTP model group), $1 \mathrm{ml} / \mathrm{kgbw}$ NSO orally (NSO group), and NSO + MPTP (MPTP model and NSO intervention group) respectively, for 5 consecutive days.

Following respective administrations, the mice were placed on video surveillance for one hour each, to observe their behavioural responses to the respective regimens, especially the MPTP.

\subsection{Measurement of Body Weight}

The body weights of the animals were measured at the commencement and end of the study using a digital weighing balance (KERRO ${ }^{\circ}, 2016 ; 0.1 \mathrm{~g}$ accuracy) in order to check for weight gain and/or loss across the groups.

\subsection{Novel Object Recognition (NOR) Test}

The Novel Object Recognition (NOR) test was performed for each group of mice, 24 hours after the final administration. The test involved the habituation, training and testing phases as adapted from the (SBFNL(b), 2019) protocol. During the habituation phase, each mouse was introduced into an open field maze ( $38 \mathrm{~cm} \times 38 \mathrm{~cm} \times 38 \mathrm{~cm}$ ) to get habituated for 5 mins. During the training phase, each mouse was placed into the open field maze for another 5 mins, this time containing objects $A$ and $B$, both of which are similar in shape, colour, size and height. They were placed diagonally within the maze and equidistant from each other. During the testing phase however, the mice were again introduced into the open field maze, but this time, with object $B$ already replaced with a novel object $C$ at the same location. This phase also lasted for 5 minutes. The test was tracked with a video camera, and the time spent by each animal in exploring the novel object $\mathrm{C}$ was recorded against the time spent exploring the familiar object $\mathrm{A}$ and the discrimination index was determined as a percentage of the novel object exploration time over the total time spent exploring both objects.

\subsection{Open Field Test}

The open field test was performed as adapted from the (SBFNL(c), 2020) protocol. Mice were picked at random from the group concerned and placed at the centre of the maze to commence the test. Movement of the mice over the maze grids was surveilled and the number of lines crossed, grooming postures, walling postures and hinding (rearing) postures were recorded. Each mouse spent a total of 5 minutes in the maze.

\subsection{Balance beam walk test}


The balance beam walk test was performed in line with earlier defined protocols (Luong et al., 2011). The mice were picked randomly and placed on the end of the rods facing away from the balance beam. The time it took the animal to turn $180^{\circ}$ and the time taken for the animal to reach the safety zone at the attachment point of the rod were both recorded. Each mouse was also given 5minutes to undergo the test.

\subsection{Sacrifice}

Following administration and neurobehavioral assays, the animals were euthanized. Each group of mice was randomly divided into two categories. The first were sacrificed by prompt decapitation, for immediate excision and homogenization of the striatum, frontal Cortex and cerebellum in $0.1 \mathrm{M}$ phosphate buffered saline (PBS) for further respective neurotransmitter assay. The others were euthanized with $0.1 \mathrm{ml}$ ketamine hydrochloride (i.p.), followed by transcardiac perfusion with $0.9 \%$ normal saline for two minutes, and then $0.1 \mathrm{M}$ phosphate buffered saline (PBS). Perfused brain tissues from the latter were subsequently fixed in formal calcium solution for twenty-four hours and taken through the routine H\&E processing.

\subsection{Brain Weights}

The respective weights of the excised brains were measured, and the relative brain weights (RBW) of the animals across the groups was calculated using the formula:

RBW $=($ Brain Weight/Body Weight at sacrifice $) \times 100$

\subsection{Dopamine assay}

For the determination of Dopamine, the tissue homogenate was mixed directly with 6-Aminoquinoly-Nhydroxy-succinimidy carbonate (AQC) at room temperature (Bergh et al., 2016; Gottås et al., 2015). The resultant samples were reacted with ninhydrin reagent to form a colour reaction. A $100 \mathrm{ml}$ of ninhydrin reagent was prepared by mixing $16 \mathrm{ml}$ of $0.6 \mathrm{M}$ with $58.8 \mathrm{~g} / \mathrm{Litre}$ Phosphoric acid, $64 \mathrm{ml}$ of glacial acetic and $1 \mathrm{~g}$ ninhydrin. Thus, $550 \mu \mathrm{l}$ of ninhydrin reagent was added to every $50 \mu \mathrm{l}$ of the sample (mixture containing $A Q C$ ) in $5 \mathrm{ml}$ screw capped pyrex tubes. Known concentrations of Standard solution of the neurotransmitter (Dopamine) were prepared as the sample. The tubes were heated for one hour in $100^{\circ} \mathrm{C}$ water bath. Afterwards, the tubes were cooled at room temperature and $160 \mathrm{ml}$ of formic acid was added in these tubes. Optical densities were thereafter read at $310 \mathrm{~nm}$ wave length concentrations of the tested sample. Dopamine concentration was then calculated as follows:

Dopamine $\left(\mu \mathrm{gg}^{-1}\right)=[$ Absence Reading X slope $($ Standard $)] \div($ Dilution factor $\times 10,000)$

\subsection{Statistical analysis}

Data acquired were expressed as mean \pm standard error of mean, and were analyzed with one-way analysis of variance (ANOVA) using the GraphPad Prism (version 7.0) software. Statistical significance was set at $p<0.05$. 


\section{Results}

The following are the recorded results at the end of the research.

\subsection{Physical observations}

Following the first administration session, the MPTP mice expressed mild tremor, restlessness and reduced locomotion across distances within the cage, while their food and water consumption rates increased appreciably.. The feed consumption rate for the NS group was however lower than the control, even though, all other groups apart from the MPTP maintained their normal levels of activity after their respective administrations throughout the study. The activity levels of the NS + MPTP mice however increased slightly upon commencement of MPTP administration, even though this did not reach the level of the MPTP mice. Furthermore, an idiopathic scoliosis (IS) developed in one of the MPTP mice on the fourth day of administration, as illustrated in appendix I. The animal was thereafter isolated for observation and possible recuperation. However, the animal never recovered until it died three days afterwards.

\subsection{Body Weight Changes}

We describe the mean difference in body weights (final weight - initial weight) of the animals (Fig. 1), where the MPTP mice had the highest and thus significantly higher mean body weight gain than mice of all other groups. Also, NS group had the least gain in weight when compared with the Control group while NS + MPTP group had a significantly lesser body weight gain than the MPTP group even though higher than the NS group.

\subsection{Relative Brain Weight}

The following are percentages of brain-to-body weight ratios obtained from the present study (Figure 2). While the administration of MPTP led to a significantly higher (and in fact highest) relative brain weights as seen in MPTP group, pre-administration of Nigella sativa rather prevented and counter-acted this hike, resulting in an insignificantly lower RBW in the NS+MPTP group than the control and MPTP groups. The NS group however maintained a slightly higher RBW than the Control and NS+MPTP groups.

\subsection{Novel Object Recognition Test}

A significantly higher novel exploration time was observed for the induced Parkinson's-like group (MPTP)than all other groups (Fig. 3). Pre-treatment of such Parkinson's-like group with Nigella sativa as seen in 'NS + MPTP' yielded a novel exploration time similar mice administered the treatment alone (NS)without the induction of Parkinson's. NS + MPTP and MPTP however had higher exploration time than the control mice.

\subsection{Open Field Maze Test}


Of the open field parameters assessed (Fig. 4), there was a decrease in the locomotion of the MPTP mice as evident in the significantly decreased number of lines crossed and frequency of walling when compared with other groups.Both were however prevented in the NS + MPTP group as seen in the significantly higher line crossings maintained, similar to the level recorded in the NS group.

\subsection{Balance Beam}

In this balance beam walk assay (Figure 5), we found the fastest turning interval and rod traversing time in the NS mice, while on the converse, MPTP and NS+MPTP groups took longer times than the control, with MPTP being the slowest to reach the safety point, even though it took a shorter time than the pretreated NS+MPTP to turn 180 degrees.

\subsection{Dopamine Assay}

The following are the results obtained from the dopamine assay

As seen in Fig. 6,striatal dopamine level was significantly down-regulated in the MPTP mice, while the fronto-cortical and cerebellar dopamine levels in the MPTP mice were rather at par with or higher than in NS mice respectively.The NS + MPTP mice therefore had a higher striatal dopamine level than the parkinsonic (MPTP) mice.

\subsection{Hematoxylin and Eosin Stains}

Figure 7 above shows the striatal, fronto-cortical and cerebellar histology across the experimental mice, with striatal neurons and nigrostriatal bundles indicated in full and dashed arrows respectively. The neuronal density in the MPTP mice was the least while the NS+MPTP mice expressed significantly higher striatal neurons than in all other groups. No significant variation was observed across the fronto-cortical and cerebellar histological architectures.

\section{Discussion}

MPTP had been characterised as a neurotoxin in humans and rodents, with irreversible Parkinson's-like features such as tremor, rigidity, and slowness of movement (bradykinesia), postural instability, and freezing. The above motor symptoms were observed in the present study upon administration of MPTP, in validation of earlier reports by Aarslandet al. (2009), Jellinger(1998), and Meredith \& Rademacher (2011), in which rigidity, slowness of movement, postural instability, and freezing were reported in MPTPadministered humans, non-human primates, cats, rabbits, and some rodents strains. Furthermore, this study further shows that BALB/c mice are also sensitive to MPTP with respect to these Parkinson's-like features. However, these parkinsonic traits were absent in the mice pre-administered with Nigella sativa (NS + MPTP), indicating the prophylactic potential of Nigella sativa in preventing these Parkinson's-like symptoms. 
Upon macroscopic examination, no detectable insult or injury was observed in the brains across all groups. However, idiopathic scoliosis (IS) was observed in one of the MPTP-administered mice. Described as a multifactorial disease involving many intrinsic factors such as genetics, imbalance of muscle structures, abnormal growth of vertebral bodies, asymmetrical growth of the neurocentral cartilage, length discrepancy between spine and spinal cord, abnormal platelet calmodulin, and abnormality in melatonin metabolism (Banala et al., 2018; Machida, 2018); the idiopathic scoliosis observed in one of the MPTP mice may however be an epiphenomenon rather than being consequential to the MPTP administered, as has been said of many hypothesised factors (Machida, 2018).

Human PD patients have been reported to experience low body weight, a phenotype hypothesised to be predisposed by many factors like dysphagia, chewing difficulty, impaired hand-mouth coordination, and hyposmia (Bachmann \& Trenkwalder, 2006; Ma et al., 2018). Similar body weight trend has also been reported of non-human primates (Porras et al., 2012). Despite this trend however, no significant weight loss was recorded in C57BL/ 6 mice by Sundström et al. (1990) during 4 weeks after MPTP exposure. A further obvious contrast to the trend above was the observable body weight changes in the current study, in which the MPTP mice had the highest mean body weight increase compared with all other groups.

While this may be explained by the increased food and water consumption rates observed in the mice, it is a further validation of the report in which $32.9 \%$ of PD patients studied by Cersosimo et al.(2018) showed increase in their body weights. This study thus shows MPTP as increasing MBW in BALB/c mice. The increased appetite and the consequent body weight gain also raises the question about the tendency of MPTP or perhaps some of its active constituents to to predispose exposed animals to obesity, as found in the BALB/c mice here studied. It may also be inferred that MPTP does not adversely affect the weight and that the growth rate is also normal in BALB/c's mice, an effect that is yet to be understood.

However, the weight gain in the NS mice was significantly lower and in fact the least when compared to other groups. This is similarly explained by the feed consumption rate which was lower in the NS group than observed in all other groups. Reduced weight gain as recorded in this study, is a phenomenon that has been previously characterised to Nigella sativa exposure, in line with the findings of Bano et al. (2009) and Le et al. (2004), such that its significantly repressive effect on weight gain is obvious. This weight limiting effect of Nigella sativa was thus seen on the NS + MPTP mice which had a significantly lesser MBW than the MPTP group but higher than the NS group. Nigella sativa was thus able to limit the weight gain in this group, suggesting its ability to repress/counter the weight increasing effects of MPTP.

Relative brain weight (RBW), also known as brain-to-body weight ratio, is a hypothetical estimate of the brain functions of an animal, as it is believed to coincide much better with the observed cognitive abilities than absolute brain size (Cairó, 2011). In this study, the highest RBW was recorded in the MPTP mice, possibly due to a progression of the brain weight along with the body weights of the MPTP animals as discussed above. The NS + MPTP mice however recorded significantly lower RBW than the MPTP mice, indicating the impact of NS pre-exposure in keeping the RBW at par with the level recorded in the NS mice. 
Novel object recognition test (NORT) is a measure of recognition memory which harnesses the innate tendency of mice to explore novelty of their environment (SBFNL(b), 2019). The MPTP mice showed the highest exploration time with the novel object in the assay, when compared with other groups, thus accruing the highest recognition memory to the MPTP mice. This finding is inconsistent with the previous reports in which mild cognitive impairment and dementia are established as pathophysiological features of Parkinson's disease at the early and later stages respectively (Weil et al., 2018). Recognition memory deficit particularly has been further documented by some studies in patients with Parkinson's disease (Chiaravalloti et al., 2014). The improved recognition memory found in this study may be explained by the higher brain-body weight ratio found in the MPTP mice, since the later, as earlier explained is hypothesised as a measure of brain function.

MPTP is a known neurotoxin with neurodegenerative potentials in human and animals (Langston, 2017). However, the memory and brain weight findings in the BALB/c mice administered with MPTP raises questions about possible advantageous impacts of this neurotoxin on some brain functions, even if such impacts are species or strain dependent.

The novel exploration time of the MPTP mice was significantly higher than recorded in the NS + MPTP mice, with the latter value similar to that of the NS mice. This may suggest the impact of Nigella sativa in moderating the novel object exploration time in the pre-treated mice.

The NS group behaved best by spending the least time to turn and the least time to reach the end of the beam. The MP animals however spent the longest time to reach the end of the beam, similar to the significantly $(p<0.0001)$ longer time reported of the Aphakia mice (also known as akmouse, which is a striatal denervation model of Parkinson's disease exhibiting the cell specificity of neurodegeneration observed in humans) to complete the balance beam test (Singh et al., 2007). Nigella sativa was however able to reduce this traversing interval for NSMP but not the turning time. This suggests a therapeutic effect of Nigella sativa on motor balance and coordination in Parkinsonic mice.

The neurotransmitter assay revealed the lowest striatal dopamine in the MPTP mice, in validation of previous studies which characterised Parkinsonism with deficiency of dopamine and dopaminergic neurons in the midbrain, especially in the striatum (Scherman et al., 1989; Triarhou, 2013). The striatal dopamine levels in the NS and control group however were similar and both were significantly higher than in the MPTP mice. This may explain the up-regulated dopamine level recorded in the NS + MPTP mice in comparison with the parkinson's-like MPTP mice. This indicates the prophylactic role of Nigella sativa in Parkinsonism. The cerebellar dopamine level in the MPTP mice was however higher than all other experimental groups, albeit insignificantly statistically, while in the frontal cortex, there was almost no difference in the dopamine levels across the mice. This corroborates the localisation of Parkinsonic dopamine depletion to the striatum (Folarin et al., 2019; Meredith \& Rademacher, 2011; Scherman et al., 1989; Sedaghat et al., 2014; Singh et al., 2007).

The striatal neuronal density in the MPTP mice was the least, in validation of reports by Ross et al., (2004) where the mean neuronal densities in all striatal quadrants were significantly lower in the PD 
group compared with the other groups. This thus confirms the depletion of striatal neurons in BALB/c strains of MPTP mice models of Parkinsonism, in slight contrast to its being referred to as MPTPresistant (Meredith \& Rademacher, 2011). However, when pre-treated with Nigella sativa oil, striatal neuronal density was markedly preserved than in mice administered with MPTP only and Nigella sativa oil only.. The fact, however, that the NS + MPTP mice expressed more striatal neurons than the MPTP mice, corroborates the prophylactic potential of Nigella sativa against Parkinsonic endophenotypes as earlier described with other data above. Strains of mice are known to differ in their response to MPTP with respect to the degree of striatal DA depletion, amount of loss of midbrain DA neurons, and behavioural deficits. However, while the hallmark of sensitivity and resistance in the substantia nigra pars compacta (SNpc) was put at " $>50 \%$ SNpc neuron loss" and " $<25 \%$ SNpc loss" respectively (Meredith \& Rademacher, 2011), the neuronal loss recorded in the BALB/c MPTP mice was only significant statistically, but not up to $20 \%$ of the control's neuronal density. A ">50\% loss" was however recorded in the dopamine assays in the MPTP mice.

In the cerebellum and frontal cortex however, no significant morphological or pathological difference was observed between the groups across the molecular, ganglionic and granular layers of their cerebellar cortices; and across the layers of the frontal cortex.

\section{Conclusion}

In this study, MPTP was validated with some known Parkinsonic features such as tremor, downregulation of dopamine and reduced density of striatal neurons in the BALB/c mice. The BALB/c mice may thus be considered MPTP-sensitive as regards these Parkinsonic features. But MPTP also increased the appetite, body weight, brain-body weight ratio, and recognition memory in the MPTP-administered mice. Nigella sativa was found to ameliorate the negative Parkinson's-like features earlier mentioned, as induced by MPTP administration, and also moderated the up-regulations effected by MPTP, as shown in its prophylactic roles against striatal neuronal and dopamine down-regulation.

Conclusively, oral administration of Nigella sativa oil prevented functional loss of striatal dopaminergic neurons in Parkinson's-like mice as investigated through the histological and neurotransmitter assays of MPTP-induced BALB/c mice, even though insignificant difference was observed in the frontal cortex and cerebellum of the same mice. By and large, this study corroborates the possible candidacy of Nigella sativa in the treatment of Parkinson's disease.

\section{Declarations}

\section{Conflict of Interest}

The authors declare no conflict of interest.

\section{Acknowledgements}


FRO shows immense gratitude to Prof. Marina Bentivoglio and Pof. Evelyne Sernagor of the IBRO/ISN Writing papers workshop, 2019, for their guidance.

\section{Funding}

The research was executed without any external funding support.

\section{Conflicts of interest/Competing interests}

The authors have no conflicting or competing interests to declare

\section{Availability of data and material}

Data will be made available upon justifiable requests.

\section{Code availability}

Not applicable

\section{Authors' contributions}

The work was conceived, designed and drafted by RF, who also coordinated the acquisition, analysis, and interpretation of data by AO, PO and PF. IA revised it critically for important intellectual content while all authors approved the version to be published and agree to be accountable for all aspects of the work.

\section{Ethics approval}

Ethical clearance (numbered BS/18/VII/23-010) was obtained for the study from the Anatomical Research Ethics Committee (AREC), Olabisi Onabanjo University, Sagamu, Nigeria.

\section{Consent to participate}

Not applicable

\section{Consent for publication}

Not applicable

\section{References}

1. Aarsland D, Londos E, Ballard C (2009) Parkinson's disease dementia and dementia with Lewy bodies: Different aspects of one entity. Int Psychogeriatr 21(02):216. https://doi.org/10.1017/S1041610208008612

2. Ahmad A, Husain A, Mujeeb M, Khan SA, Najmi AK, Siddique NA, Damanhouri ZA, Anwar F (2013) A review on therapeutic potential of Nigella sativa: A miracle herb. Asian Pacific Journal of Tropical 
Biomedicine 3(5):337-352. https://doi.org/doi:10.1016/S2221-1691(13)60075-1

3. Al-Naqeep G, Al-Zubairi AS, Ismail M, Amom ZH, Esa NM (2011) Antiartherogenic Potential of Nigella sativa Seeds and Oil in Diet-Induced Hypercholesterolaemia in Rabbits. Evidence-Based Complementary and Alternative Medicine, 213628

4. Assi MA, Mohd Noor MH, Bacheck NF, MOHD AHMAD,HHARON,AW, YUSOFF MS, \& RAJION, M. A (2016) The Various Effects of Nigella Sativa on Multiple Body Systems in Human and Animals. Pertanika Journal of Scholarly Research Reviews 2(3):1-19

5. Bachmann CG, Trenkwalder C (2006) Body weight in patients with Parkinson's disease. Movement Disorders: Official Journal of the Movement Disorder Society 21(11):1824-1830. https://doi.org/10.1002/mds.21068

6. Banala RR, Vemuri SK, Penkulinti M, Av GR, Gpv S (2018) Development of Novel Animal Model for Studying Scoliosis Using a Noninvasive Method and Its Validation through Gene-Expression Analysis. Asian Spine Journal 13(1):126-134. https://doi.org/10.31616/asj.2018.0108

7. Bano F, Wajeeh M, Baig N, Naz H, Akhtar N (2009) Antiobesity antihyperlipidemic hypoglycemic effects of the aqueous extract of Nigella Sativa seeds (Kalongi) 42(4):136-140

8. Bergh MS-S, Bogen IL, Lundanes E, Øiestad ÅML (2016) Validated methods for determination of neurotransmitters and metabolites in rodent brain tissue and extracellular fluid by reversed phase UHPLC-MS/MS. J Chromatogr B 1028:120-129. https://doi.org/10.1016/j.jchromb.2016.06.011

9. Cairó O (2011) External Measures of Cognition. Frontiers in Human Neuroscience, 5. https://doi.org/10.3389/fnhum.2011.00108

10. Cersosimo MG, Raina GB, Pellene LA, Micheli FE, Calandra CR, Maiola R (2018) Weight Loss in Parkinson's Disease: The Relationship with Motor Symptoms and Disease Progression [Research article]. BioMed Research International. https://doi.org/10.1155/2018/9642524

11. Chiaravalloti ND, Ibarretxe-Bilbao N, DeLuca J, Rusu O, Pena J, García-Gorostiaga I, Ojeda N (2014) The source of the memory impairment in Parkinson's disease: Acquisition versus retrieval. Movement Disorders: Official Journal of the Movement Disorder Society 29(6):765-771. https://doi.org/10.1002/mds.25842

12. Dingman M (2015, February 15) Know your brain: Striatum. Neuroscientifically Challenged. https://neuroscientificallychallenged.com/blog/know-your-brain-striatum

13. Drag LL, Bieliauskas LA, Kaszniak AW, Bohnen NI, Glisky EL (2009) Source memory and frontal functioning in Parkinson's disease. Journal of the International Neuropsychological Society: JINS 15(3):399-406. https://doi.org/10.1017/S1355617709090572

14. Folarin R, Olonade A, Obadeyin E, Adeyanju M, Adenowo T, Shallie P, Owoeye O (2019) Prophylactic Role of Nigella sativa in Striatal Histology and Neurochemistry of Male Mice Models of Sub-Chronic Parkinsonism. IBRO Reports 7:10. https://doi.org/10.1016/j.ibror.2019.09.025

15. Gottås A, Ripel Å, Boix F, Vindenes V, Mørland J, Øiestad EL (2015) Determination of dopamine concentrations in brain extracellular fluid using microdialysis with short sampling intervals, analyzed 
by ultra high performance liquid chromatography tandem mass spectrometry. J Pharmacol Toxicol Methods 74:75-79. https://doi.org/10.1016/j.vascn.2015.06.002

16. Ichinohe N, Mori F, Shoumura K (2000) A di-synaptic projection from the lateral cerebellar nucleus to the laterodorsal part of the striatum via the central lateral nucleus of the thalamus in the rat. Brain Res 880(1-2):191-197. https://doi.org/10.1016/s0006-8993(00)02744-x

17. Jellinger KA (1998) Neuropathology of movement disorders. Neurosurg Clin N Am 9(2):237-262

18. Langston JW (2017) The MPTP Story. Journal of Parkinson's Disease 7(Suppl 1):S11-S19. https://doi.org/10.3233/JPD-179006

19. Le PM, Benhaddou-Andaloussi A, Elimadi A, Settaf A, Cherrah Y, Haddad PS (2004) The petroleum ether extract of Nigella sativa exerts lipid-lowering and insulin-sensitizing actions in the rat. J Ethnopharmacol 94(2-3):251-259. https://doi.org/10.1016/j.jep.2004.04.030

20. Luong TN, Carlisle HJ, Southwell A, Patterson PH (2011) Assessment of Motor Balance and Coordination in Mice using the Balance Beam. Journal of Visualized Experiments: JoVE, 49. https://doi.org/10.3791/2376

21. Ma K, Xiong N, Shen Y, Han C, Liu L, Zhang G, Wang L, Guo S, Guo X, Xia Y, Wan F, Huang J, Lin Z, Wang T (2018) Weight Loss and Malnutrition in Patients with Parkinson's Disease: Current Knowledge and Future Prospects. Frontiers in Aging Neuroscience, 10. https://doi.org/10.3389/fnagi.2018.00001

22. Machida M (2018) Neurological Research in Idiopathic Scoliosis. In M. Machida, S. L. Weinstein, \& J. Dubousset (Eds.), Pathogenesis of Idiopathic Scoliosis (pp. 157-188). Springer Japan. https://doi.org/10.1007/978-4-431-56541-3_7

23. Meredith GE, Rademacher DJ (2011) MPTP Mouse Models of Parkinson's Disease: An Update. Journal of Parkinson's Disease 1(1):19-33. https://doi.org/10.3233/JPD-2011-11023

24. NINDS (2019) Parkinson's Disease Information Page. National Institute of Neurological Disorders and Stroke (NINDS). https://www.ninds.nih.gov/Disorders/All-Disorders/Parkinsons-DiseaseInformation-Page\#disorders-r1

25. Porras G, Li Q, Bezard E (2012) Modeling Parkinson's Disease in Primates: The MPTP Model. Cold Spring Harbor Perspectives in Medicine, 2(3). https://doi.org/10.1101/cshperspect.a009308

26. Randhawa MA, Alenazi SA (2016) Neuropsychiatric Effects of Nigella sativa (Black Seed) - A Review. Alternative Integrative Medicine, 05(01). https://doi.org/10.4172/2327-5162.1000209

27. Roberts AC, De Salvia MA, Wilkinson LS, Collins P, Muir JL, Everitt BJ, Robbins TW (1994) 6Hydroxydopamine lesions of the prefrontal cortex in monkeys enhance performance on an analog of the Wisconsin Card Sort Test: Possible interactions with subcortical dopamine. The Journal of Neuroscience: The Official Journal of the Society for Neuroscience 14(5 Pt 1):2531-2544

28. Ross GW, Petrovitch H, Abbott RD, Nelson J, Markesbery W, Davis D, Hardman J, Launer L, Masaki K, Tanner CM, White LR (2004) Parkinsonian signs and substantia nigra neuron density in decendents elders without PD. Ann Neurol 56(4):532-539. https://doi.org/10.1002/ana.20226 
29. SBFNL(b) (2019) 2-Object Novel Object Recognition. Stanford Behavioral and Functional Neuroscience Laboratory. https://med.stanford.edu/sbfnl/services/bm/lm/bml-novel.html

30. SBFNL(c) (2020) Open Field. Behavioral and Functional Neuroscience Laboratory. https://med.stanford.edu/sbfnl/services/bm/sm/openfield.html

31. Scherman D, Desnos C, Darchen F, Pollak P, Javoy-Agid F, Agid Y (1989) Striatal dopamine deficiency in Parkinson's disease: Role of aging. Ann Neurol 26(4):551-557. https://doi.org/10.1002/ana.410260409

32. Sedaghat R, Roghani M, Khalili M (2014) Neuroprotective effect of thymoquinone, the nigella sativa bioactive compound, in 6-hydroxydopamine-induced hemi-parkinsonian rat model. Iranian Journal of Pharmaceutical Research: IJPR 13(1):227-234

33. Singh B, Wilson JH, Vasavada HH, Guo Z, Allore HG, Zeiss CJ (2007) Motor Deficits and Altered Striatal Gene Expression in aphakia(ak) Mice. Brain Res 1185:283-292. https://doi.org/10.1016/j.brainres.2007.09.006

34. Sundström E, Fredriksson A, Archer T (1990) Chronic neurochemical and behavioral changes in MPTP-lesioned C57BL/6 mice: A model for Parkinson's disease. Brain Res 528(2):181-188. https://doi.org/10.1016/0006-8993(90)91656-2

35. Triarhou LC (2013) Dopamine and Parkinson's Disease. Landes Bioscience. https://www.ncbi.nlm.nih.gov/books/NBK6271/

36. Weil RS, Costantini AA, Schrag AE (2018) Mild Cognitive Impairment in Parkinson's Disease-What Is It? Curr Neurol Neurosci Rep, 18(4). https://doi.org/10.1007/s11910-018-0823-9

37. Williams DR, Litvan I (2013) Parkinsonian Syndromes. Continuum: Lifelong Learning in Neurology 19(5 Movement Disorders):1189-1212. https://doi.org/10.1212/01.CON.0000436152.24038.e0

38. Wu T, Hallett M (2013) The cerebellum in Parkinson's disease. Brain 136(3):696-709. https://doi.org/10.1093/brain/aws360

\section{Figures}



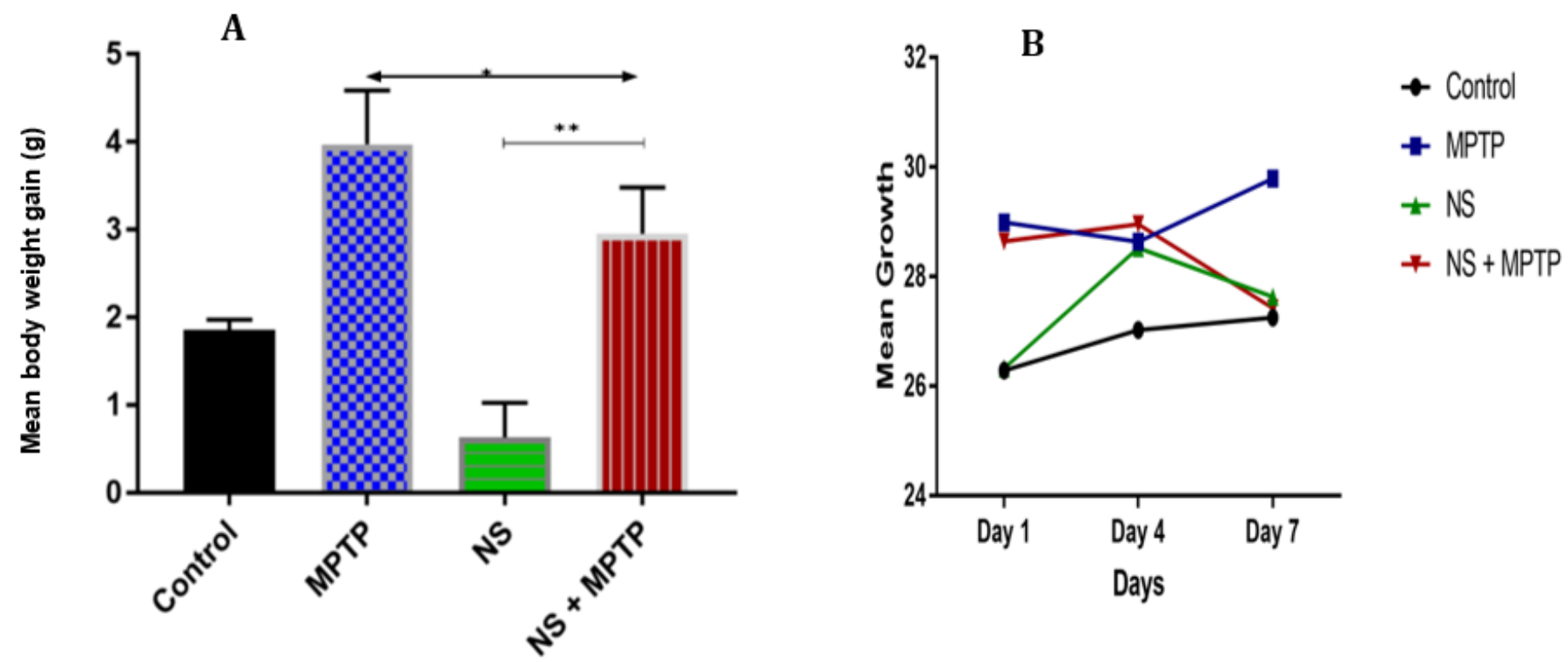

Figure 1

Graphs showing the mean body weight gain (A) and Mean Growth Curve (B) of the animals in different groups during the experiment ( $*$ and $* \star$ indicate increasing levels of significance at $p<0.05$ )

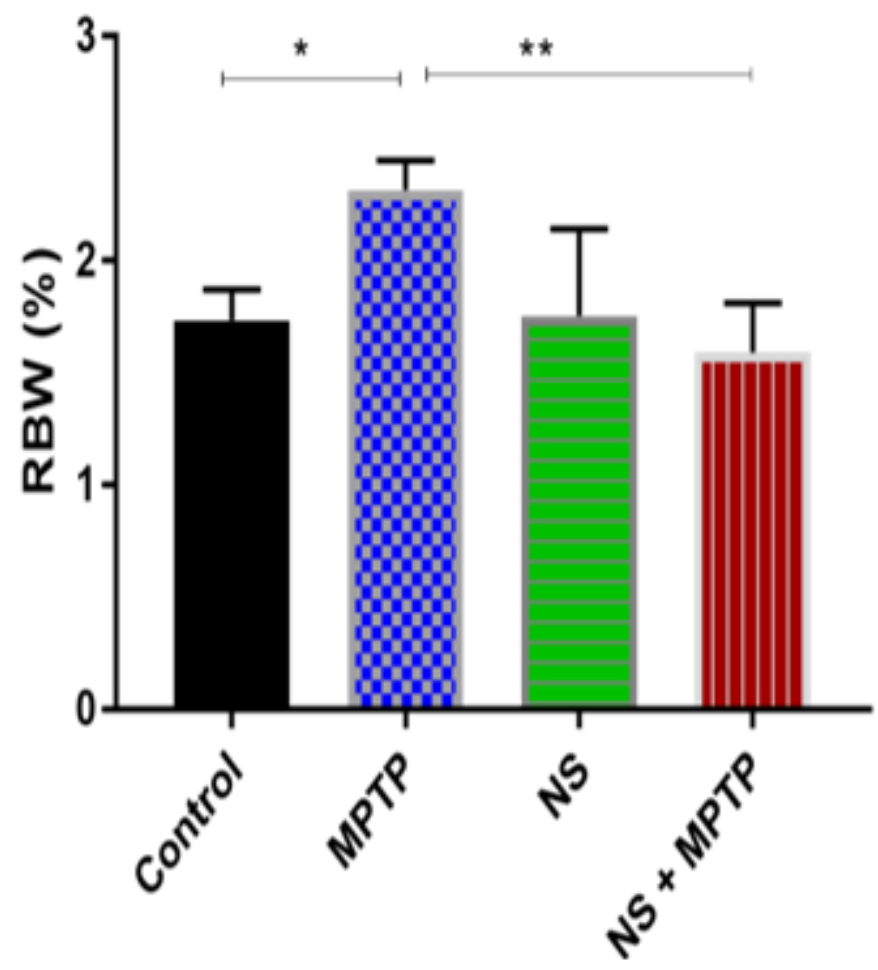

Figure 2

Graph Illustrating Relative Brain Weights (RBW) in Experimental Mice (* and ** indicate increasing levels of significance at $p<0.05$ ) 


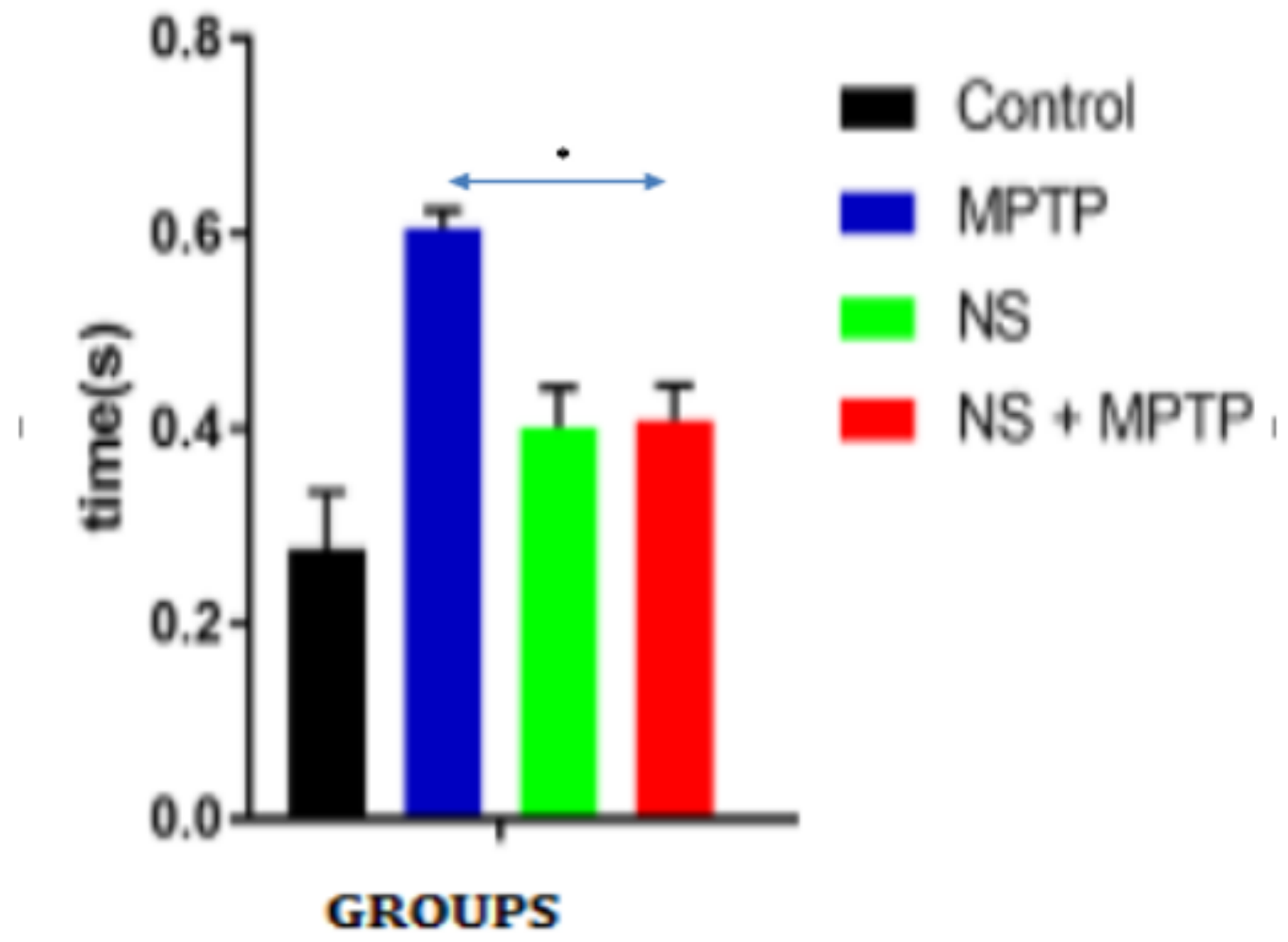

Figure 3

Graph showing Novel Object Recognition in Experimental Mice (* and ** indicate increasing levels of significance at $\mathrm{p}<0.05$ ) 


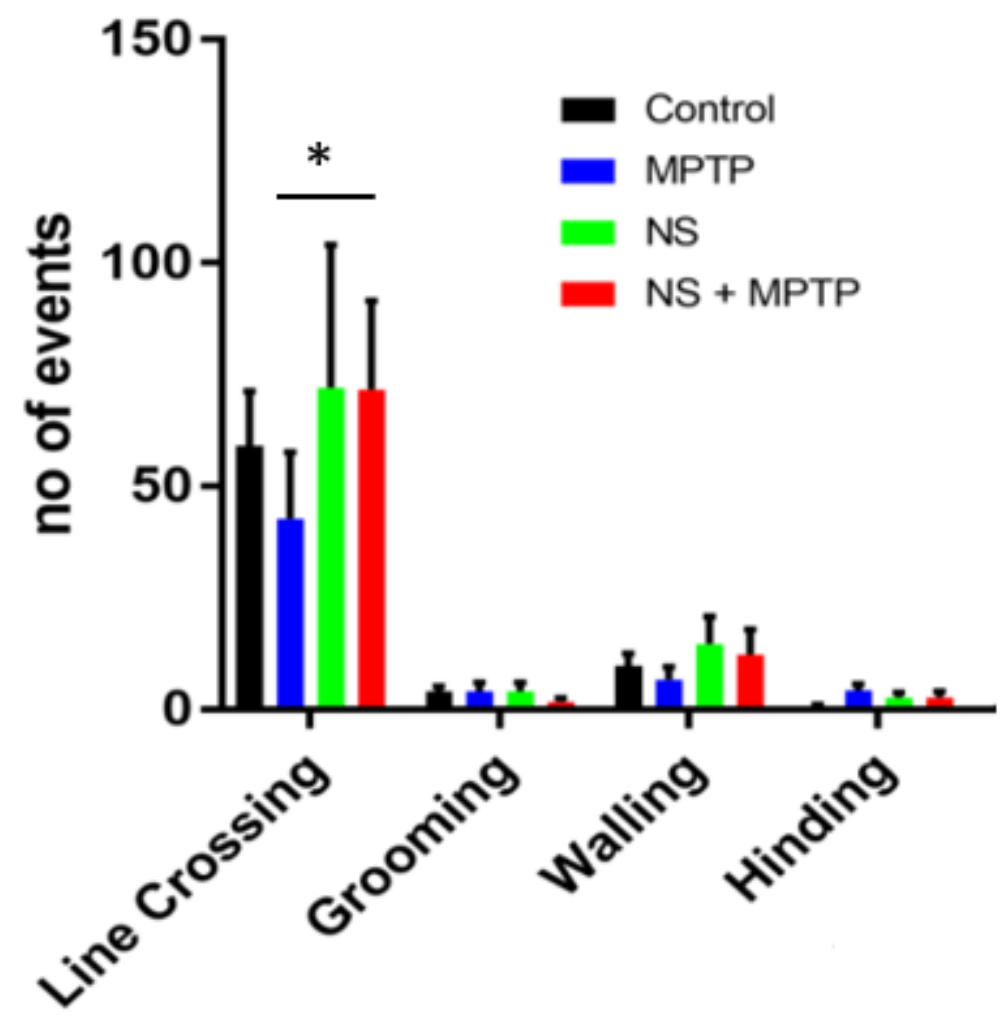

Figure 4

Showing Open Field Maze test in Experimental Mice. ( ${ }^{*}$ indicates significance at $p<0.05$ )
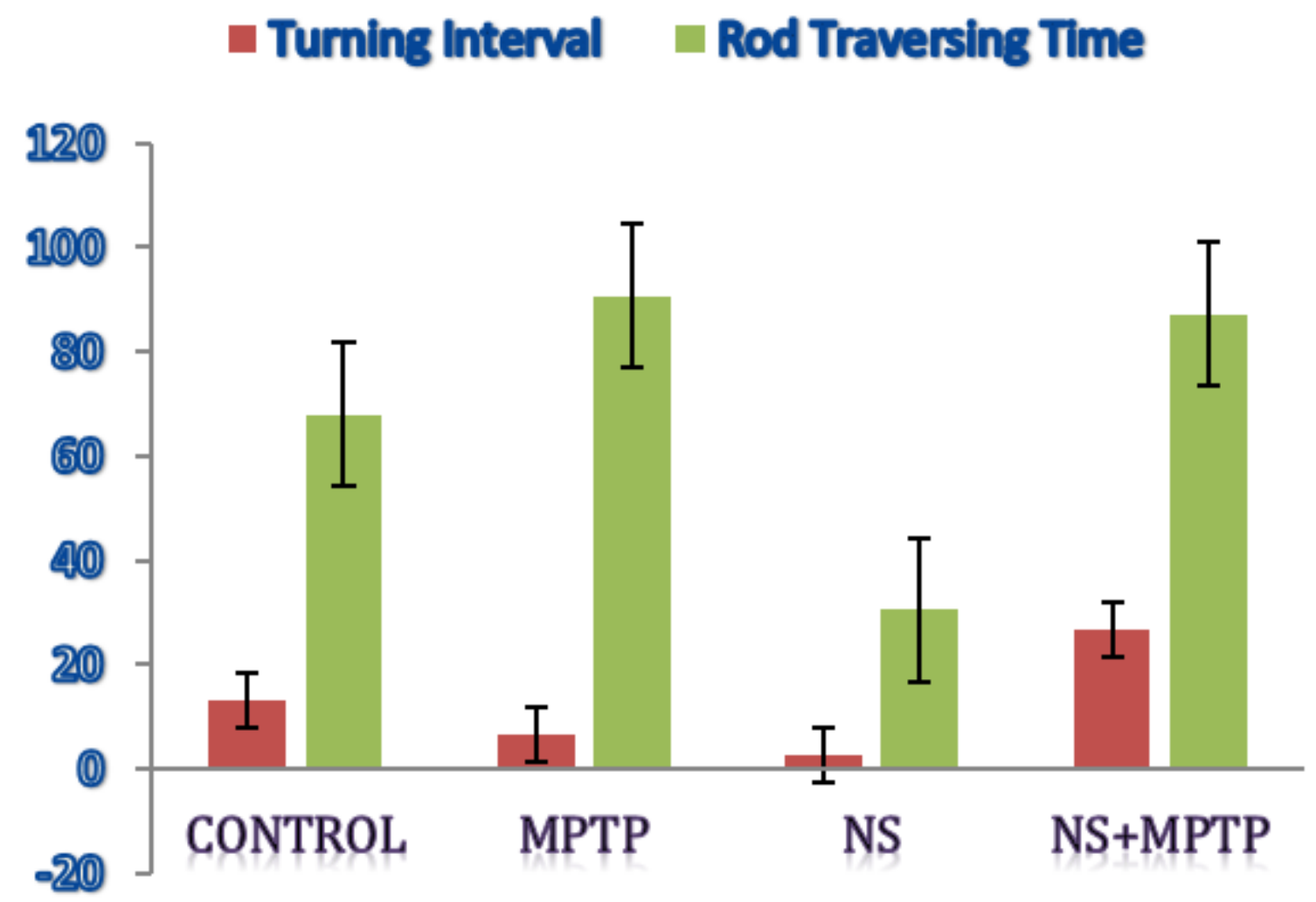


\section{Figure 5}

Graph showing animals' scores on the balance beam walk test
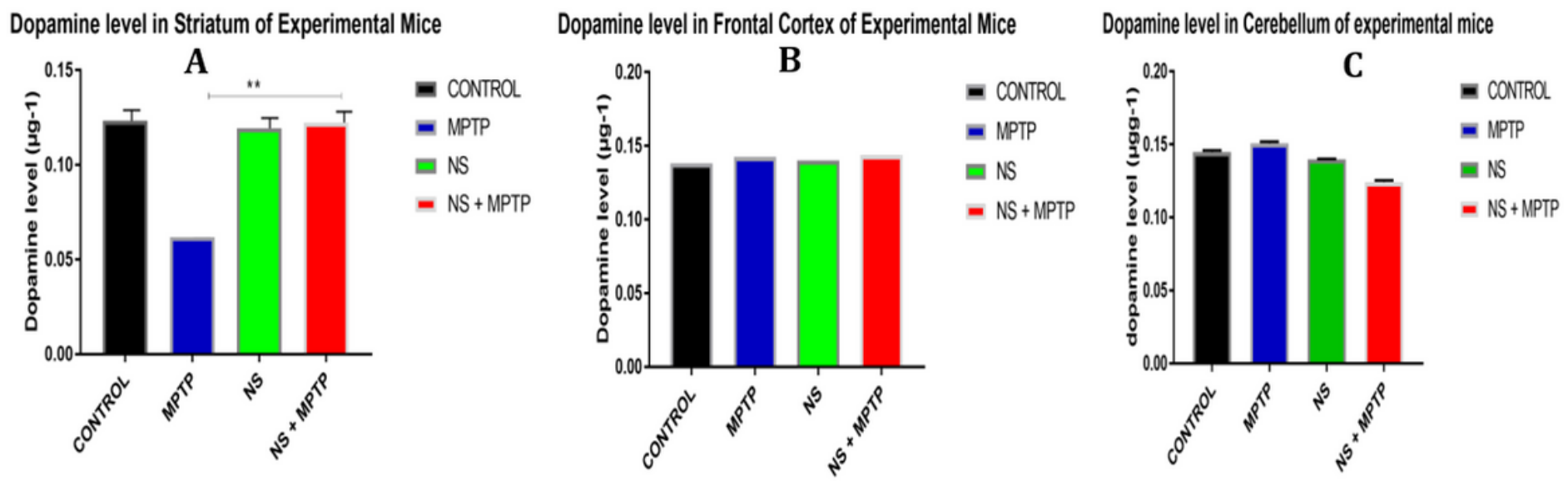

Figure 6

Graph illustrating Dopamine level in Striatum, Frontal cortex and Cerebellum of the Mice ${ }^{*}$ and ${ }^{\star \star}$ indicate increasing levels of significance at $p<0.05$ )
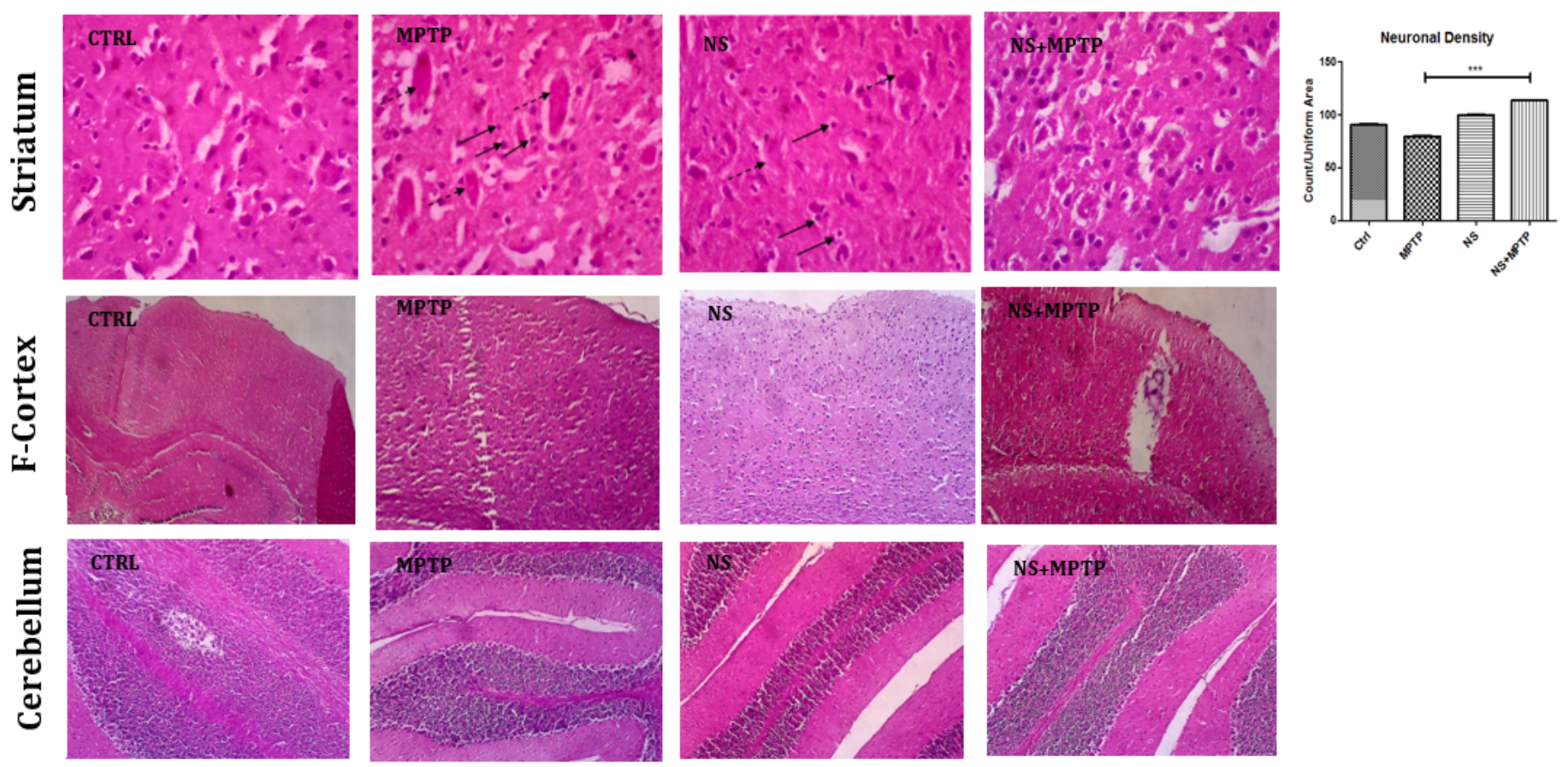

Figure 7

Photomicrographs of the Striatum stained with $\mathrm{H} \& \mathrm{E}$ stains across all mice groups. Magnification = (X400). Full arrows indicate striatal neurons, while dashed arrows indicate nigrostriatal bundles.

\section{Supplementary Files}


This is a list of supplementary files associated with this preprint. Click to download.

- Appendixl.docx 